\title{
Eficácia dos tratamentos estabelecidos pelo Manual da IETS, em oócitos, expostos à Leptospira interrogans
}

\author{
[Effectiveness of treatments established by the Manual of IETS, in oocytes, exposed to \\ Leptospira interrogans] \\ A.C. Goes ${ }^{1,2}$, M.M. Piccolomini ${ }^{1,2}$, V. Castro ${ }^{1}$, M. D'Angelo ${ }^{1}$ \\ ${ }^{1}$ Centro de Pesquisa e Desenvolvimento de Sanidade Animal - Instituto Biológico - São Paulo, SP \\ ${ }^{2}$ Aluna de pós-graduação - Instituto Biológico - São Paulo, SP
}

\begin{abstract}
RESUMO
Avaliou-se a eficácia dos tratamentos, definidos pela International Embryo Transfer Society (IETS), de oócitos bovinos, maturados in vitro e expostos experimentalmente à Leptospira interrogans sorovar Grippotyphosa. Os oócitos foram obtidos por meio de punção folicular, selecionados e distribuídos em quatro grupos, expostos ao patógeno e submetidos aos diferentes tipos de tratamentos. Foram expostos à cepa na concentração de $4,7.10^{5} / \mu \mathrm{L}$, virulenta e não adaptada ao meio de manutenção EMJH, e, de $6,3.10^{5} / \mu \mathrm{L}$, avirulenta e adaptada ao meio, por 24 horas. Os grupos tratados com tripsina ou antibióticos apresentaram eficácia de $21,7 \%$, e o grupo lavado sequencialmente $33,4 \%$. Os tratamentos não foram eficazes para os contaminados com a cepa avirulenta. Concluiu-se que as normas de controle de qualidade estabelecidas pela IETS poderiam ser revisadas e, possivelmente, redefinidas, uma vez que a eficácia dos tratamentos, provavelmente, não depende somente da espécie do patógeno, pois há interferência da virulência e de ação dos tratamentos sobre o tipo de patógeno.
\end{abstract}

Palavras chave: oócito, Leptospira interrogans, Grippotyphosa, produção in vitro

\begin{abstract}
The research purpose was to evaluate the effectiveness of treatments established by the IETS, in bovine oocytes maturated in vitro, exposed experimentally to Leptospira interrogans serovar Grippotyphosa. The oocytes were obtained through follicular puncture, selected and randomly allotted in four groups, exposed to the pathogen and subjected to different types of treatments. They were exposed to the strain in the concentration of $4.7 \times 10^{5} / \mu \mathrm{L}$ virulent and not adapted to the EMJH, and to $6,3 \times 10^{5} / \mu \mathrm{L}$, virulent and adapted to the medium, for 24 hours. The treatments presented for the groups with trypsin or antibiotics, $21.7 \%$ efficiency, and the group washed sequentially presented $33.4 \%$ efficiency. The treatments were not effective for those infected with avirulent strain. In the statistical analysis, by $\chi^{2}$, was found significance in the results obtained. The standards of quality control established by IETS could be reviewed and possibly redefined, since the effectiveness of treatment probably depends not only on the species of the pathogen, but is also affected by its virulence and treatment effectiveness.
\end{abstract}

Keywords: oocytes, Leptospira interrogans, Grippotyphosa, in vitro production

\section{INTRODUÇÃO}

No agronegócio, a pecuária é um dos principais produtos de exportação brasileira, principalmente o de carne bovina. Desse modo, a utilização de biotécnicas na reprodução dos rebanhos é de grande importância para alcançar esse patamar
(Gonçalves et al., 2007). A transferência de embriões (TE), utilizada mundialmente para introdução, melhora e preservação de animais geneticamente superiores, e a produção in vitro (PIV), alternativa usada nos programas de reprodução, pois além de sua relevância para estudos biotecnológicos possui fundamento

Recebido em 10 de maio de 2010

Aceito em 6 de abril de 2011

E-mail: acgoes@biologico.sp.gov.br 
comercial, são valiosas ferramentas para difundir e acelerar a produção animal e, também, constituem excelente recurso para pesquisa de aspectos biológicos que ocorrem durante a maturação, a fecundação e o cultivo in vitro de oócitos e embriões (Gonçalves et al., 2007).

Durante o período de maturação, as células da granulosa expandem-se e conectam-se à zona pelúcida (ZP), permitindo a entrada do espermatozoide. Dessa maneira, autores questionaram se haveria interação entre 0 relaxamento das células da ZP e agentes infecciosos, que poderiam levar o patógeno às receptoras ou tornar o embrião doente ou portador (Bielasnki et al., 1997). Acredita-se que a ação dos patógenos sobre embriões ocorra somente após a penetração do agente na célula, porém, no caso de patógenos com tamanho reduzido, como os vírus, ou ativamente invasivos, como algumas bactérias, a ZP, mesmo intacta, passa a não ser uma barreira intransponível (Dangelo et al., 2005).

Stringffellow et al. (1999) citaram a capacidade de alguns patógenos penetrarem no oócito ou embrião através da ZP, tais como Herpes vírus bovino tipo 4 (BoHV-4), vírus da rinotraqueite infecciosa bovina (IBRV), vírus da peste bovina (RPV), vírus da estomatite vesicular (VSV), Haemophilus somnus, Mycoplasma bovis, Mycoplasma bovigenitalium, Mycoplasma paratuberculosis e Ureoplasma diversum. Concluíram que a lavagem e o tratamento na PIV, com tripsina, devem reduzir o nível de contaminação, mesmo que a eficácia desses tratamentos não seja totalmente comprovada.

Para que haja controle sanitário dos embriões e oócitos na PIV, a International Embryo Transfer Society (IETS) desenvolveu um manual de procedimentos, com instruções de tratamentos celulares com tripsina ou antibióticos em lavagens alternadas com meio de cultura e, também, lavagens sequenciais, com a finalidade de inativar ou remover agentes infecciosos que podem interferir no produto final (Stringfellow et al., 1990).

As leptospiras são bactérias espiroquetas, gramnegativas, aeróbias obrigatórias, helicoidais flexíveis e móveis, fortemente espiraladas. Possuem de 0,1 a $0,3 \mu \mathrm{m}$ de diâmetro por 6 a $30 \mu \mathrm{m}$ de comprimento, dois filamentos axiais (flagelo periplasmático) com inserções polares localizadas no espaço periplasmático, o que facilita seu movimento de rotação e flexão rápida em seu próprio eixo (Ellinghausen et al., 1981; Faine, 1994). A transmissão da leptospira, em bovinos, pode ocorrer de maneira direta, principalmente através de via venérea e, de modo indireto, pelo contato com o solo e água contaminados (Amafredjo et al., 1975). A via de transmissão transplacentária também é comum entre os animais (Manual..., 1995). Guimarães (1982) descreveu que os danos causados pela $L$. interrogans em bovinos, em fases agudas e crônicas, caracterizam-se por abortamentos, retenção placentária, queda na produção de leite, mastite, infertilidade e infecção renal permanente.

O objetivo do trabalho foi avaliar a eficácia dos tratamentos com tripsina, antibióticos ou lavagem sequencial, estabelecidos pela IETS, em oócitos maturados in vitro e expostos, experimentalmente, à Leptospira interrogans sorovar Grippotyphosa, durante o período de maturação, pela técnica de microscopia de campo escuro.

\section{MATERIAL E MÉTODOS}

Foram utilizadas estirpes Leptospira interrogans, sorovar Grippotyphosa, sendo uma virulenta e a outra avirulenta. Para a reativação da virulência, utilizou-se o método clássico de passagens sucessivas em hamsters, de acordo com procedimentos descritos por Gonzales et al. (1999). O procedimento foi aprovado pela Comitê de Ética na Experimentação Animal CETEA-IB (protocolo 81/09).

Os oócitos foram obtidos de vacas abatidas em frigorífico. Na fase de evisceração, retiraram-se os ovários, que foram mantidos e transportados em solução fisiológica acrescida de $1 \%$ de antibióticos a $38^{\circ} \mathrm{C}$. Foram aspirados folículos com diâmetro entre 2 e $8 \mathrm{~mm}$, com seringa e agulha calibre $18 \mathrm{G}$, descartáveis, e selecionados complexos cumulus-oócitos (COCs) classificados como grau 1 e 2 (De Loos et al., 1989) ao estereomicroscópio em aumento de $20 X$.

Os oócitos selecionados, transferidos para gotas de meio de maturação (TCM199, 10\% de Soro Fetal Bovino, 0,5 $\mu \mathrm{l}$ de FSH, 50UI/mL de hCG, $1 \mu \mathrm{L}$ de $17-\beta$ estradiol $/ \mathrm{mL}$ ) de $50 \mu \mathrm{L}$ cada, foram 
distribuídos em quatro grupos, todos expostos ao patógeno para serem submetidos aos tratamentos com: - antibióticos - penicilina 10.000UI/mL e estreptomicina $10 \mathrm{mg} / \mathrm{mL} ; 2$ - lavagem com tripsina $0,25 \% ; 3$ - lavagem sequencial (TCM199); 4 - sem tratamentos, usado como controle positivo. $\mathrm{O}$ controle negativo não foi exposto ao patógeno, porém foi submetido ao mesmo tratamento. Esse procedimento foi realizado para cada estirpe separadamente.

A exposição dos oócitos ao patógeno foi realizada no volume de $30 \mu \mathrm{L}$ da estirpe de L. interrogans sorovar Grippotyphosa na concentração de $4,7.10^{5} / \mu \mathrm{L}$, virulenta e não adaptada ao meio de manutenção EMJH; um outro grupo foi contaminado com o mesmo volume, de outra estirpe, na concentração de $6,3 \cdot 10^{5} / \mu \mathrm{L}$, avirulenta e adaptada ao meio EMJH. Cada gota de meio de maturação continha 20 oócitos, que foram, então, levados à estufa de $\mathrm{CO}_{2} 5 \%$ em ar, umidade relativa de $90 \%$ e temperatura de $37^{\circ} \mathrm{C}$, por 18 a 24 horas.

Após 18 a 24 horas de incubação e maturação, os grupos foram tratados, conforme metodologia descrita pelo manual da IETS (Stringfellow, 1998), sendo 10 gotas de $200 \mu \mathrm{L}$ cada, em 1-4 meio TCM199, 5-6 com antibióticos e 7-10 com meio TCM199. Para as lavagens com tripsina, as gotas 5-6 foram substituídas, e para lavagem sequencial, as 10 gotas continham TCM199, com troca de microponteira a cada etapa do tratamento.

Após as lavagens, os grupos foram observados ao microscópio óptico Jena Zeiss ${ }^{\circledR}$ em aumento de 400X, onde foram avaliados quanto à presença e/ou ausência da L. interrogans.

\section{RESULTADOS E DISCUSSÃO}

A avaliação da presença da bactéria, em movimento e/ou interagindo com os oócitos, após os tratamentos, foi realizada por microscopia de campo escuro, onde se verificou a eficácia parcial dos tratamentos validados pela IETS. Para os oócitos expostos à cepa de $L$. interrogans sorovar Grippotyphosa, virulenta, na concentração de $4,7 \times 10^{5} / \mu \mathrm{L}$, os tratamentos apresentaram, para os grupos tratados com tripsina e antibióticos, $21,7 \%$ de eficácia (39/180), e para o grupo lavado sequencialmente, $33,4 \%$ de eficácia (60/180). O controle negativo apresentou efetividade de 100\% (160/160).
Utilizando-se como parâmetro a presença da bactéria ativa no campo do oócito, tais resultados sugerem que, por se tratar de uma bactéria não adaptada ao meio de manutenção, não houve tempo hábil para sua fixação ao oócito - sendo, então, removida mecanicamente -, ou mesmo sua visualização ativa, após os tratamentos.

Para os oócitos expostos à cepa de L. interrogans sorovar Grippotyphosa na concentração de $6,3 \times 10^{5} / \mu \mathrm{L}$, avirulenta, os tratamentos não foram eficazes para nenhum dos grupos contaminados, de 160 oócitos para cada grupo, e de 140 para cada grupo controle negativo, novamente evidenciando a adaptação ao meio de manutenção EMJH.

Pelo teste do qui-quadrado, verificou-se efetividade dos tratamentos, $\mathrm{P}=0,001$, entre os grupos controle e contaminado.

A PIV, por ser uma importante ferramenta para acelerar e aumentar a produção de animais geneticamente superiores e gerar conhecimento nas áreas relacionadas, tornou-se alvo de inúmeras pesquisas no que diz respeito à qualidade do produto final, principalmente nas interações e interferências que os patógenos podem causar ao longo do processo, gerando prejuízos ao setor pecuário (Gonçalves et al., 2007). Os riscos, associados à possível transmissão de patógenos por meio de embriões, podem estar intimamente ligados às propriedades da ZP. Assim sendo, procedimentos para descontaminá-la são importantes pontos nos protocolos sanitários de manipulação propostos pela IETS (Wrathall e Stmoller, 1998). A IETS padronizou procedimentos e inferiu informações gerais para uso da tecnologia de TE, enfatizando produções sanitárias, por parte da Organização Mundial de Saúde (OIE), sobre o manuseio asséptico de oócitos e embriões, com o objetivo de descrever técnicas necessárias para assegurar que a TE não resulte em transmissão de agentes patogênicos (Stringfellow, 1998).

Diversos autores testaram os procedimentos estabelecidos pela IETS. Stringfellow et al. (1990), ao avaliarem a efetividade dos tratamentos com tripsina para inativação dos vírus IBRV e BHV-4, em 24 e 29 embriões PIV, respectivamente, verificaram que $100 \%$ dos embriões foram positivos para o patógeno, após o tratamento, por meio do isolamento do vírus 
por cultivo celular. Singh e Thomas (1982) constataram que a lavagem sequencial foi eficaz em $64 \%$ das amostras e, com o tratamento com tripsina, foi de $57 \%$, para embriões infectados com IBRV, isolando o agente pelo cultivo celular.

Segundo Lauerman et al. (1986), de 130 embriões bovinos contaminados experimentalmente com VSV, $36 \%$ apresentavam o vírus após a lavagem sequencial, evidenciado pela ausência dele no isolamento em células Vero. Singh e Thomas (1987) confirmaram que essa porcentagem é significativa para a lavagem sequencial ao submeterem 46 embriões ao tratamento com tripsina, e constatarem sua eficácia em $63 \%$ das amostras. Stringfellow et al. (1989) comprovaram que a eficácia pode atingir $50 \%$ dos casos, em oócitos infectados, para ambos os tratamentos.

Thomson et al. (1988) realizaram testes de eficácia do tratamento com antibióticos e com lavagem sequencial, para Haemophilus somnus, contaminando embriões com $10^{10} \mathrm{UFC} / \mathrm{mL}$. De 38 embriões contaminados e lavados sequencialmente, isolou-se a bactéria em 26 deles. Porém, para 20 embriões contaminados e submetidos ao tratamento com antibiótico, a eficácia atingiu $100 \%$ das amostras.

Bielanski et al. (1989) mostraram que, de 71 embriões bovinos infectados previamente com Mycoplasma bovis, após a lavagem sequencial, e de 40 embriões tratados com antibióticos, foi isolado o agente em $100 \%$ das amostras, e mesmo após o tratamento com tripsina, o microrganismo foi isolado em todas as amostras. Também foi isolado por Riddell, Stringfellow et al. (1989) em 100\% das amostras, Mycoplasma bovigenitalium, sendo os embriões bovinos lavados sequencialmente $(n=24)$, tratados com antibiótico $(n=25)$ e com tripsina $(n=22)$. Rohde et al.(1990) isolaram Mycoplasma paratuberculosis em oócitos bovinos PIV, após a lavagem sequencial, em $30 \%$ das amostras.

Trachte et al. (1998) verificaram que grupos expostos a amostras de BVDV não citopático, tratados com tripsina e lavados sequencialmente, apresentavam $56 \%$ de eficácia para embriões e $33 \%$ para oócitos, após tratamento com tripsina. Porém, com BVDV citopático, embriões e oócitos apresentaram $67 \%$ de eficácia para a lavagem sequencial, $78 \%$ de eficácia para o tratamento com tripsina em embriões e $56 \%$ em oócitos. Bielanski e Surujballi (1996) testaram os procedimentos em oócitos coletados in vivo de novilhas infectadas com BVDV e constataram que os tratamentos não eliminaram ou inativaram o patógeno dos oócitos.

Edens et al. (2003) verificaram, por meio de cocultivo de embriões expostos à BoHV-1 em microgotas de TCM199 que o tratamento com tripsina pode, efetivamente, impedir a infecção das receptoras. D'Angelo et al. (2009) submeteram embriões bovinos tratados com tripsina ao BoHV-1. A última gota inoculada em células MDBK foi submetida à prova de N-PCR, tendo resultado negativo para a presença do patógeno. Porém, a detecção do patógeno, pelo mesmo teste, foi positiva para os embriões. Esses resultados mostraram a ineficácia do tratamento, dando suporte à premissa de que enzimas proteolíticas diminuem a quantidade de patógenos, ou, até mesmo, o inativam, desde que já não estejam no interior da estrutura estudada.

Bielanski et al. (1998) testaram a eficácia das lavagens sequenciais, por microscopia, em embriões fertilizados in vitro, expostos à Leptospira borgpeersenii sorovar Hardjo, e observaram que o patógeno encontrava-se na superfície da ZP, eletrônica. Vale ressaltar que os autores utilizaram uma quantidade sabidamente excessiva do patógeno, para realmente poderem observar sua interação com o embrião.

Goes et al. (2008) estudaram a eficácia dos tratamentos com tripsina e com antibióticos na inativação/remoção de Leptospira interrogans sorovar Canicola, em oócitos, avaliados quanto à presença da bactéria, por microscopia de campo escuro, demonstrando que os tratamentos não foram capazes de remover o microrganismo, enfatizando, assim, a necessidade de se estabelecer normas de controle de qualidade na PIV.

Devido ao fato de a leptospira ser uma doença que acomete animais de corte e a prática da PIV estar em crescimento acelerado, a análise dos resultados obtidos no presente trabalho mostra que a implantação de normativas de controle de qualidade na produção de embriões in vitro deve ser estabelecida e, principalmente, atualizada. 


\section{CONCLUSÕES}

A lavagem sequencial mostrou-se mais eficaz, quando comparada aos tratamentos com tripsina ou antibióticos, para cepa virulenta de Leptospira interrogans sorovar Grippotyphosa.

\section{AGRADECIMENTOS}

Ao CNPq, ao Laboratório de Doenças Bacterianas da Reprodução - Instituto Biológico, ao abatedouro Mantiqueira - São José dos Campos, SP e à Empresa Vitrocell/Embriocare.

\section{REFERÊNCIAS}

AMATREDJO, A.; CAMPBELL, R.S.F.; PATHR, M.R.C. Bovine leptospirosis. Vet. Bull., v.45, p.875-891, 1975.

BIELANSKI, A.; EAGLESOME, M.D.; RUHNKE, H.L. et al. Isolation of Mycoplasma bovis from intact and microinjected preimplantation bovine embryos washed or treated with trypsin or antibiotics. J. In Vitro Fert. Embryo Transfer, v.6, p.236-241, 1989.

BIELANSKI, A.; SURUJBALLI, O. Association of Leptospira interrogans serovar hardjo type hardjobovis with bovine ova and embryos produced by in vitro fertilization. Theriogenology, v.46, p. 45-55, 1996.

BIELANSKI, A.; LUTZE-WALLACE, C.; SAPP, T. JORDAN, L. The efficacy of trypsin for disinfection of in vitro fertilized bovine embryos expose to bovine herpesvirus 1. Anim. Reprod. Sci., v.47, p.1-8, 1997.

BIELANSKI, A.; SURUJBALLI, O.; THOMAS, G.E. et al. E. Sanitary status of oocytes and embryos collected from heifers experimentally. Anim. Reprod. Sci., v.54, p.65-73, 1998.

D'ANGELO, M.; GALUPPO, A.G.; PIATTI, R.M. et al. Avaliação de sensibilidade de zigotos murinos ao herpesvírus bovino-1: um modelo experimental para estudos de interações embrião-vírus. Arq. Inst. Biol., v.72, p.141-145, 2005.

D'ANGELO M.; VISINTIN, J.A.; RICHTZENHAIN, L.I. et al. Evaluation of trypsin treatment on the inactivation of bovine herpesvirus type 1 on in vitro produced pre-implantation embryos. Reprod. Dom. Anim., v.44, p.536-539, 2009.
De LOOS, F.; VAN VLIET, C.; VAN MAURIK, P. Morphology ovarian of immature bovine oocytes. Gamete Res., v.24, p.197-204, 1989.

EDENS, M.S.; GALIK, P.K.; RIDDELL, K.P. et al. Bovine herpesvirus-1 associated with single, trypsin-treated embryos was not indective for uterine tubal cells. Theriogenology, v.60, p.1495504, 2003.

ELLINGHAUSEN, H.C,; THIERMANN, A.B.; SULZER, C.R. Leptospirosis. In: BALOWS, A.; HAUSLER, W.J. Bacterial, mycotic and parasitic infections. American Public Health Associantion, Washington. 1981. p.463.

FAINE, S. Leptospira and leptospirosis. Melbourne: CRC Press, 1994. 353p.

GOES, A.C.; PICCOLOMINI, M.M.; CASTRO, V. et al. Estudo preliminar da avaliação dos tratamentos com tripsina e antibiótico na inativação da Leptospira interrogans, sorovar Canicola, em oócitos bovinos maturados in vitro. In: REUNIÃO ANUAL DO INSTITUTO BIOLÓGICO, 21., 2008, São Paulo. Biológico, v.70,p.107-216, 2008.

GONÇALVES, P.B.D.; BARRETA, M.H.; SANDRI, L.R. et al. Produção in vitro de embriões bovinos: o estado da arte. Rev. Bras.Reprod. Anim., v.31, p.212-217, 2007.

GONZÁLEZ, Y.H.; DÍAZ, E.M.F.; MATOS, B.O. Método para revitalizar las cepas de Leptospira interrogans utilizadas en los ensayos de potencia de la vacuna antileptospirósica. Health I.G. News, v.3, p.7-10, 1999.

GUIMARÃES, M. C. Epidemiologia e controle da leptospirose em bovinos. Papel do portador e o seu controle terapêutico. 1982, 50f. Dissertação (Mestrado em Epidemiologia Experimental e Aplicada a Zoonoses) - Faculdade de Medicina Veterinária e Zootecnia, Universidade de São Paulo, São Paulo, SP.

LAUERMAN, L.H.; STRINGFELLOW, D.A.; SPARLING, P.H. et al. In vitro exposure of preimplantation bovine embryos to vesicular stomatitis virus. J. Clin. Microbiol., v.24, p.380383, 1986.

MANUAL de Leptospirose. 2.ed. Brasília: Ministério da Saúde, 1995. 98p.

RIDDELL,K.P.; STRINGFELLOW, D.A.; PANANGALA, V.S. Interaction of Mycoplasma bovis and Mycoplasma bovigenitalium with preimplantation bovine embryos. Theriogenology, v.32, p.633-641, 1989. 
ROHDE, R.F.; SHULAW, W.P.; HUESTON, W.D. et al. Isolation of Mycoplasma paratuberculosis from washed bovine ova after in vitro exposure. Am. J. Vet. Res., v.51, p.708-710, 1990.

SINGH, E.L.; THOMAS, F.C. Embryos transfer as a means of controlling the transmission of viral infections: the in vitro exposure of bovine and porcine embryos to infectious bovine rhinotracheitis virus. Theriogenology, v.18, p.133140, 1982.

SINGH, E.L.; THOMAS, F.C. Embryos transfer as a means of controlling the transmission of viral infections: the in vitro exposure of bovine and porcine embryos to vesicular stomatitis virus. Theriogenology, v.28, p.691-697, 1987.

STRINGFELLOW, D.A.; LAUERMAN, L.H.; THOMSON, M.S. Trypsin treatment of bovine ova after in vitro exposure to vesicular stomatitis virus. Am. J. Vet. Res., v.50, p.990-992, 1989.

STRINGFELLOW, D.A.; LAUERMAN, L.H.; NASTI, K.B. et al. Trypsin treatment of bovine ova after in vitro exposure to infectious bovine rhinotacheitis virus or bovine herpes virus-4. Theriogenology, v.34, p. 427-434, 1990.
STRINGFELLOW, D. A. Recomendações para o manuseio sanitário de embriões obtidos in vivo. In: STRINGFELLOW, D.A.; S EIDEL, S.M. (Eds.). Manual da Sociedade Internacional de Transferência de Embriões. Jaboticabal: SBTE, 1998. p.83-96.

THOMSON, M.S.; STRINGFELLOW, D.A.; LAUERMAN, L.H. Adherence of Haemophilus somnus to bovine embryos after in vitro exposure. Am. J. Vet. Res., v.49, p.63-66, 1988.

TRACHET, E.; STRINGFELLOW, D.; RIDDELL, K. et al. Washing and trypsin treatment of in vitro derived bovine embryos exposed to bovine viral diarrhea virus. Theriogenology, v.50, p.717-726, 1998.

WRATHALL, A.E.; STMOLLER, P. Potencial da transferência de embriões para controlar a transmissão de doenças. In: STRINGFELLOW, D.A.; SEIDEL, S.M. Manual da Sociedade Internacional de Transferência de Embriões. 3.ed. EUA: IETS, Cap.2, p.17-45,1998. 